\title{
Early diagnosis and critical management of wound botulism in the emergency department: a single center experience and literature review
}

\author{
Michael M. Neeki ${ }^{1,2^{*}}$ D , Fanlong Dong ${ }^{1}$, Chuck Emond ${ }^{1}$, Carol Lee ${ }^{1,2}$, Arianna S. Neeki ${ }^{1}$, Keeyon Hajjafar ${ }^{1}$,
} Megan Messinger ${ }^{1}$, Caitlyn O. Anderson ${ }^{1}$, Reza Hajjafar ${ }^{1}$ and Rodney Borger ${ }^{1,2}$

\begin{abstract}
Background: Clostridium botulinum remains a major threat to a select population of subcutaneous and intramuscular drug users. We conducted a retrospective study of patients who were diagnosed with wound botulism and their clinical presentations to the Emergency Department (ED).

Results: A total of 21 patients met the inclusion criteria and all had a confirmed history of heroin use disorder. Initial presentation to the ED included generalized weakness ( $n=20,95 \%)$, difficulty swallowing $(n=15,71 \%)$, and speech/voice problems $(n=14,79 \%)$. Sixteen patients $(76 \%)$ also presented with visible skin wounds and fifteen (71\%) required mechanical ventilation (MV). Patients who presented with dysphagia as well as dysarthria and/or dysphonia were more likely to require a percutaneous endoscopic gastrostomy (PEG) tube. Patients who required MV and PEG tubes were noted to have a longer hospital length of stay (LOS) due to the severity of the disease progression.
\end{abstract}

Conclusions: Emergency physicians should remain vigilant about early recognition of wound botulism, especially in patients who inject drugs.

Keywords: Wound botulism, Intravenous drug use, Intramuscular drug use, Skin popping

\section{Introduction}

Wound botulism is a life-threatening disease with rapidly worsening clinical course. In the USA, wound botulism is associated with subcutaneous injection of black tar heroin and has a mortality of $13.2 \%[1,2]$. The introduction of black tar heroin (BTH) in the 1990s led to an increase in non-intravenous injection, most often into the subcutaneous tissue ("skin popping") and sometimes into muscle. Both methods require less accuracy than IV

\footnotetext{
* Correspondence: michaelneeki@gmail.com

'Department of Emergency Medicine, Arrowhead Regional Medical Center, 400 N. Pepper Ave, Suite \# 107, Colton, CA 92324, USA

${ }^{2}$ California University of Science and Medicine, San Bernardino, CA 92324, USA
}

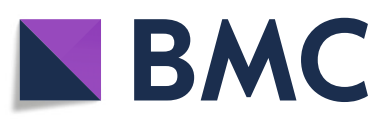

() The Author(s). 2021 Open Access This article is licensed under a Creative Commons Attribution 4.0 International License, which permits use, sharing, adaptation, distribution and reproduction in any medium or format, as long as you give appropriate credit to the original author(s) and the source, provide a link to the Creative Commons licence, and indicate if changes were made. The images or other third party material in this article are included in the article's Creative Commons licence, unless indicated otherwise in a credit line to the material. If material is not included in the article's Creative Commons licence and your intended use is not permitted by statutory regulation or exceeds the permitted use, you will need to obtain permission directly from the copyright holder. To view a copy of this licence, visit http://creativecommons.org/licenses/by/4.0/. The Creative Commons Public Domain Dedication waiver (http://creativecommons.org/publicdomain/zero/1.0/) applies to the data made available in this article, unless otherwise stated in a credit line to the data.

injection, remain viable after superficial venous access is exhausted, and result in slower absorption of the drug $[1,3]$. BTH is still the predominant form of heroin in the USA, and California alone accounts for threequarters of all wound botulism cases in the country [2]. This method of BTH administration and the associated likelihood of infection by Clostridium botulinum (C. botulinum) has increased morbidity and complications in individuals [1].

There are many opportunities to become contaminated with C. botulinum in the production and distribution process for $\mathrm{BTH}$, and the spores will survive substances and temperatures that kill other bacteria. The 
drug is frequently cut with anything of a similar dark brown color, including dirt and wood pulp, which may introduce $C$. botulinum spores. Spores have also been found on drug paraphernalia [1]. Subcutaneous injection then creates an ideal anaerobic breeding ground for $C$. botulinum and the formation of botulinum neurotoxin $[1,2]$. The sharing of contaminated needles is also common among a selected demographic of drug users and can contribute to wound botulism [4]. If an abscess develops after injection of $\mathrm{BTH}$, the anaerobic environment allows spores to germinate and the organism to thrive [5]. C. botulinum neurotoxin quickly spreads systemically via the lymphatic and vascular systems [4]. Botulism progresses rapidly, and patients may present with bulbar and other nonspecific symptoms such as weakness, dysphagia, gait disturbance, and dyspnea [4].

Early diagnosis requires high clinical suspicion and can be confirmed by electrophysiological and laboratory studies. However, the average delay between blood sample acquisition and results of the toxin assay can be up to a few days $[6,7]$. As a result, empiric antitoxin acquisition from the Centers for Disease Control and Prevention (CDC) and early administration is recommended as soon as the diagnosis is suspected clinically [7]. Since the antitoxin is only available from the $\mathrm{CDC}$, physicians should anticipate a delay between their request and the arrival of antitoxin at the requesting facility [8]. As a result, acquiring the antitoxin from the $\mathrm{CDC}$ is the ratelimiting step to initiating adequate therapy [8]. Prolonged delay of appropriate and necessary treatment can result in rapid clinical deterioration of the patient and even death [9].

Due to the rarity of botulism and clinicians' unfamiliarity with its clinical presentation, inclusion of the possibility of botulism in the differential diagnosis and subsequent treatment is often absent or delayed. Successful treatment of wound botulism is well known to be time dependent, and a delay in treatment may create a survival risk for the patient. This study aims to evaluate the most prevalent signs and symptoms of patients who presented to the emergency department (ED) with wound botulism and their course of treatment.

\section{Methods}

This study was approved by the Institutional Review Board at Arrowhead Regional Medical Center (ARMC). ARMC is a 456-bed acute-care teaching facility located in Colton, California. ARMC is an American College of Surgeons verified Level II trauma center and one of the busiest emergency departments in the state of California, with more than 100,000 annual visits, including more than 3000 traumas [10]. ARMC serves the population of the County of San Bernardino, the largest county by area in the contiguous USA and a region with a high incidence of injection drug use.

A search of the ARMC electronic health system (EHR) was conducted for adult patients diagnosed with wound botulism between 2005 and 2020, using both the International Classification of Diseases 9th edition and 10th edition codes for wound botulism. Inclusion criteria were age $>18$ years and had clinical symptoms suggestive of wound botulism (bulbar palsies and/or peripheral weakness). Confirmatory studies were performed on all patients, although five individuals either had insufficient blood sample acquisition or did not have the information in their charts. These five patients improved drastically after the administration of antitoxin and were thus included in the study as presumptive cases.

The EHR of each patient was reviewed to include data from ED encounters as well as subsequent inpatient care. The overall data included patients' age, gender, symptoms at initial ED presentation, physical exam findings, history of illicit drug use, and results of ED diagnostic studies (i.e., labs, radiographs, EKGs). Additionally, patients' clinical outcome data were collected, including hospital length of stay (LOS), mechanical ventilation, and percutaneous endoscopic gastrostomy (PEG) tube placement.

All statistical analyses were conducted using the SAS software for Windows version 9.4 (Cary, North Carolina, USA). Descriptive statistics were presented as frequencies and percentages for categorical variables, along with means and standard deviations or median and corresponding first and third quartiles for continuous variables. Wilcoxon rank-sum tests were conducted to assess whether the hospital length of stay was different between the categorical predictors. All statistical analyses were two-sided. $P$ value $<0.05$ was considered to be statistically significant.

\section{Results}

A total of twenty-one patients were diagnosed with wound botulism at ARMC between 2005 and 2020. The average age was 38.48 (standard deviation $=8.41$ ) years and seven of the patients were female. The most frequent symptoms during the initial ED encounter include history of heroin use followed by visible wound $(n=16$, $76.2 \%)$, and symmetric motor weakness ( $n=14,66.7 \%)$. It is also notable that almost half of the patients had visible abscesses $(n=10,47.6 \%)$ and more than half had ptosis $(n=12,57.1 \%)$. The detailed symptoms list is presented in Table 1.

The physical examination results were analyzed to identify the most frequently noted clinical presentations associated with wound botulism in the ED. The results are presented in Table 2. The most frequent finding was generalized weakness $(n=20,95 \%)$, followed by 
Table 1 Symptoms at initial ED presentation and diagnostic methods

\begin{tabular}{lll}
\hline & Frequency $(\boldsymbol{N}=\mathbf{2 1})$ & Percentage \\
\hline Symptoms at initial ED presentation & 21 & $100.0 \%$ \\
History of heroin usage & 16 & $76.2 \%$ \\
Visible wound & 14 & $66.7 \%$ \\
Symmetric motor weakness & 12 & $57.1 \%$ \\
Ptosis & 10 & $47.6 \%$ \\
Visible abscess & 9 & $42.9 \%$ \\
Dysarthria & 8 & $38.1 \%$ \\
Extraocular muscle palsy & 7 & $33.3 \%$ \\
Surgical wound drainage & 6 & $28.6 \%$ \\
Descending paralysis & 6 & $28.6 \%$ \\
Infected abscess & 5 & $23.8 \%$ \\
Signs of IV or subcutaneous heroin use & & $52.40 \%$ \\
Diagnostic methods & 11 & $28.60 \%$ \\
Blood sample & 6 & $19.10 \%$ \\
Unclear-antitoxin given & 4 & $19.10 \%$ \\
CDC consultation-signs and symptoms & 4 & $14.30 \%$ \\
Unclear & 3 & \\
EMG study & $40 \%$ & \\
\hline
\end{tabular}

*All other responses were either "no" or "not documented" by the physician

dysarthria/dysphonia $(n=14,79 \%)$ and dysphagia $(n=$ $15,71 \%)$. All other findings occurred in less than $50 \%$ of patients.

The effect of mechanical ventilation and PEG tube placement on hospital length of stay was also analyzed. Table 3 presents the results. Patients who were on mechanical ventilation had statistically significantly longer hospital LOS (median) compared with patients without mechanical ventilation (32 days vs 7 days, $p<0.001$ ).

Table 2 Physical examination findings at emergency department presentation

\begin{tabular}{lll}
\hline & Frequency $(\mathbf{N}=\mathbf{2 1})$ & Percentage \\
\hline Generalized weakness & 20 & $95.20 \%$ \\
Difficulty swallowing & 15 & $71.40 \%$ \\
Voice/speech problems & 14 & $66.70 \%$ \\
Respiratory difficulty & 12 & $57.10 \%$ \\
Double vision/diplopia & 11 & $52.40 \%$ \\
Extremity/wound pain & 9 & $42.90 \%$ \\
Shortness of breath & 8 & $38.10 \%$ \\
Fever & 7 & $33.30 \%$ \\
Blurry vision & 6 & $28.60 \%$ \\
Sore throat & 5 & $23.80 \%$ \\
Vomiting or diarrhea & 5 & $23.80 \%$ \\
Dizziness & 5 & $23.80 \%$ \\
\hline
\end{tabular}

Physical examination findings as documented in emergency department charts

*All other responses were either "no" or "not documented" by the physician
Similarly, patients with PEG tube insertion had statistically significantly longer hospital LOS (median) compared with patients without PEG tube insertion (48 days vs 17 days, $p<0.001$ ).

\section{Discussion}

The natural progression of wound botulism varies from mild and insidious to severe and rapidly progressive. Seven strains of C. botulinum exist (A-G), but only A and $B$ strains have been found to be associated with wound botulism secondary to injection drug use [11]. Type $\mathrm{A}$ is believed to be the most potent strain and causes the most prolonged disease course [4]. They are all gram positive, anaerobic rods with subterminal spores that thrive in the anaerobic conditions created by subcutaneous abscesses. C. botulinum produces neurotoxin that inhibits acetylcholine release by binding irreversibly

Table 3 Hospital LOS by mechanical ventilation and PEG tube status

\begin{tabular}{lll}
\hline & Hospital LOS & $P$ value \\
\hline MV & $32(22,48)$ & $<0.001$ \\
Yes & $7(3,11.25)$ & \\
No & & $<0.001$
\end{tabular}

PEG tube

$<0.001$

No $17(7,26)$

MV mechanical ventilation, $P E G$ percutaneous endoscopic gastrostomy 
to the presynaptic terminal $[6,12]$. The resulting clinical syndrome is defined by symmetrical cranial nerve palsies $[9,13]$. Mouth dryness, blurry vision, and double vision are reported as earliest neurologic complaints. More severe cases will progress to dysphagia, dysarthria, dysphonia, and peripheral muscle weakness. Furthermore, in its most severe form, a descending flaccid paralysis progresses to involve the respiratory muscles and causes neuromuscular respiratory failure $[1,4]$. Notably, patients do not demonstrate any sensory deficits [14]. Recovery is often lengthy and requires generation of new neuromuscular connections [12].

The differential diagnosis should include wound botulism for any patient with a history of BTH use, presenting with generalized weakness and/or bulbar palsies. In addition, it is suggested that ED physicians rapidly request antitoxin, as well as investigating other possible etiologies such as the Miller-Fisher syndrome (MFS) variant of Guillain-Barre syndrome (GBS), myasthenia gravis, stroke syndromes (particularly basilar stroke), Lambert-Eaton Syndrome (LES), tick paralysis, or other generalized neuropathies [9, 15]. Emergency physicians may often have LES or the MFS variant of GBS as their top two differentials, so it is essential for the clinician to differentiate these conditions from botulism. In both botulism and LES, neurotransmitter release is inhibited at the presynaptic motor end plate. However, LES is due to antibodies against presynaptic voltage-gated calcium channels, and these highly specific antibodies can be detected in $85 \%$ of LES patients [16]. The MFS variant of GBS is in the differential due to its similar cranial nerve palsies, but it typically causes a noteworthy increase in CSF protein, which can help differentiate it from botulism [2]. Due to similar etiologies, it is imperative that a thorough evaluation be initiated to differentiate these diseases. However, in the case of wound botulism, these ancillary studies, such as serum electrolytes, hemoglobin, hematocrit, computed tomography $(\mathrm{CT})$ of the brain, lumbar puncture, and other diagnostic modalities as indicated, will often be unremarkable [6].

Although neuromuscular transmission studies are often more sensitive, toxin assays are a standard part of diagnostic evaluation in patients suspected of having wound botulism [15]. Serologic testing for wound botulism requires a laboratory with adequate testing capabilities. Serum toxin assays have been reported to have sensitivities as low as $33-44 \%$, whereas neuromuscular transmission studies have been shown in some reports to be diagnostic in up to $100 \%$ of cases $[2,15]$. Nevertheless, these studies are not suitable for acute diagnosis due to delay in obtaining results. As a consequence, efforts to find a rapid diagnostic tool have shown some promise in creating a sensitive and specific test in PCRbased assays, immunoenzymatic assays, or bead-based suspension array [17].
Treatment of wound botulism with the equine-derived heptavalent (types A-G) or trivalent (types A, B, and E) antitoxin is aimed at interrupting the neurologic progression of the disease and mitigating the duration of ventilatory failure in those who are severely afflicted $[6$, 18]. The antitoxin neutralizes toxin that has not yet bound to nerve endings, which underscores the importance of early initiation of treatment. Treatment is complete after one dose because one vial generally contains more than enough antibodies to saturate unbound circulating toxin [9]. Additionally, the half-life of the antibodies is 5-8 days. Although antitoxin can be lifesaving, clinicians must be aware that $21 \%$ of patients receiving antitoxin administration will demonstrate some degree of serum sickness reaction [15]. In severe cases, abscesses must also be drained properly to eradicate the source of bacterial toxins [19].

The morbidity and mortality of wound botulism can be drastically reduced if clinicians are adept at recognizing its clinical predictors. In addition, early recognition of wound botulism and antitoxin administration is critical to minimizing morbidity and mortality [7]. A high clinical suspicion along with a diagnostic and treatment protocol would help accelerate the process [7]. We noticed several diagnostic clues upon presentation which can assist in rapid identification and risk analysis for these individuals. Of note, everyone in this study presented with weakness or fatigue and a history of skin popping. Other common complaints included bulbar palsies (visual changes, difficulty swallowing, vocal changes), shortness of breath, and gait disturbances that were noted in prior reports [4]. Common physical exam findings included skin wounds, extremity weakness, ptosis, extraocular muscle abnormalities, and hypertension [4]. It is important to know that the process of obtaining botulinum antitoxin can be very challenging and time consuming. The local and/or state public health department must first be contacted, and then they contact the $\mathrm{CDC}$. The $\mathrm{CDC}$ then arranges delivery of the antitoxin to the requesting hospital using their regional cache of the antitoxins. ED physicians are often unfamiliar with this process, which further prolongs time to administration of the antitoxin.

The generalizability of our findings may be limited. Like many retrospective reviews, the data collected in this study is limited by inconsistent documentation and recording bias. Efforts have been applied to thoroughly review EHR to ensure data accuracy.

\section{Conclusion}

Wound botulism is a potentially fatal disease with rapid progression. It is therefore important to swiftly perform an evaluation, make the diagnosis, and initiate treatment. This process often begins in the emergency department, 
and as a result, emergency physicians must have a high clinical suspicion for wound botulism and be able to recognize early signs and symptoms of the disease.

\section{Acknowledgements}

Not applicable.

\section{Authors' contributions}

MMN contributed in the study design, data collection, data interpretation, and writing of the manuscript. FD contributed in data analysis, data interpretation, and writing of the manuscript. $\mathrm{CE}, \mathrm{RH}$, and $\mathrm{MM}$ contributed in data collection and writing of the manuscript. CL and RB contributed in the study design and writing of the manuscript. ASN and KH contributed in data collection, data analysis, and writing of the manuscript. COA contributed in data collection and data interpretation. The authors read and approved the final manuscript.

\section{Funding}

There is no funding to disclose.

\section{Availability of data and materials}

Availability of data and materials were available by contacting the corresponding author.

\section{Declarations}

\section{Ethics approval and consent to participate}

This study was approved by the Institutional Review Board at Arrowhead Regional Medical Center (ARMC). The IRB approval number was 20-21.

\section{Consent for publication}

Not applicable. Data were reported in aggregated format. No patient identifiers were included in the reporting.

\section{Competing interests}

The authors declare that they have no competing interests.

Received: 7 May 2021 Accepted: 27 August 2021

Published online: 22 September 2021

\section{References}

1. Tucker RD GY, Frazee B. View from the front lines: an emergency medicine perspective on clostridial infections in injection drug users. Anaerobe. 2014; 30:108-15.

2. Yuan J, Inami G, Mohle-Boetani J, Vugia DJ. Recurrent wound botulism among injection drug users in California. Clin Infect Dis. 2011;52(7):862-6. https://doi.org/10.1093/cid/cir005.

3. Michet C, Whitelock C, Siparsky N. It takes a village: the management of extreme sequelae of skin popping. Wounds. 2021;33(1):9-19.

4. Lindström M, Korkeala H. Laboratory diagnostics of botulism. Clin Microbiol Rev. 2006:19:298-314.

5. Mechem C, Walter FG. Wound botulism. Veterinary and human toxicology. 1994:36(3):233-7.

6. Botulism in the United States, 1899-1996. Handbook for epidemiologists, clinicians, and laboratory workers (1998). https://www.cdc.gov/botulism/pdf/ bot-manual.pdf. Accessed 5 July 2021

7. Rodolico C, Barca E, Fenicia L, Anniballi F, Sinardi A, Girlanda P. Wound botulism in drug users: a still underestimated diagnosis. Neurol Sci. 2010; 31(6):825-7. https://doi.org/10.1007/s10072-010-0350-1.

8. Offerman SR, Schaefer M, Thundiyil JG, Cook MD, Holmes JF. Wound botulism in injection drug users: time to antitoxin correlates with intensive care unit length of stay. West J Emerg Med. 2009;10:251.

9. Sobel J. Botulism. Beyond Anthrax. 2009:85-105. https://doi.org/10.1007/ 978-1-59745-326-4_5.

10. Neeki M, DuMontier S, Toy J, Archambeau B, Goralnick E, et al. Prehospital trauma care in disasters and other mass casualty incidents-a proposal for hospital-based special medical response teams. Cureus. 2021;13.

11. Cooper JG, Spilke CE, Denton M, Jamieson S. Clostridium botulinum: an increasing complication of heroin misuse. Eur J Emerg Med. 2005;12(5):2512. https://doi.org/10.1097/00063110-200510000-00011.
12. Sandrock CE, Murin S. Clinical predictors of respiratory failure and long-term outcome in black tar heroin-associated wound botulism. Chest. 2001;120(2): 562-6. https://doi.org/10.1378/chest.120.2.562.

13. Galldiks N, Nolden-Hoverath S, Kosinski CM, Stegelmeyer U, Schmidt S, Dohmen C, et al. Rapid geographical clustering of wound botulism in Germany after subcutaneous and intramuscular injection of heroin. Neurocrit Care. 2007;6(1):30-4. https://doi.org/10.1385/NCC:6:1:30.

14. Kalka-Moll WM, Aurbach U, Schaumann R, Schwarz R, Seifert H. Wound botulism in injection drug users. Emerg Infect Dis. 2007;13(6):942-3. https:// doi.org/10.3201/eid1306.061336.

15. Rapoport S, Watkins PB. Descending paralysis resulting from occult wound botulism. Ann Neurol. 1984;16(3):359-61. https://doi.org/10.1002/ana.4101 60314.

16. Gilhus NE. Lambert-eaton myasthenic syndrome; pathogenesis, diagnosis, and therapy. Autoimmune Dis. 2011;2011:973808. https://doi.org/10.4061/2 011/973808.

17. Simon S, Fiebig U, Liu Y, Tierney R, Dano J, et al. Recommended immunological strategies to screen for botulinum neurotoxin-containing samples. Toxins (Basel). 2015;7:5011-34.

18. Peak CM, Rosen H, Kamali A, Poe A, Shahkarami M, Kimura AC, et al. Wound botulism outbreak among persons who use black tar heroin-San Diego County, California, 2017-2018. MMWR Morb Mortal Wkly Rep. 2019;67(5152): 1415-8. https://doi.org/10.15585/mmwr.mm675152a3.

19. Sam AH, Beynon HL. Wound botulism. N Engl J Med. 2010;363(25):2444. https://doi.org/10.1056/NEJMicm1003352.

\section{Publisher's Note}

Springer Nature remains neutral with regard to jurisdictional claims in published maps and institutional affiliations.

\section{Ready to submit your research? Choose BMC and benefit from:}

- fast, convenient online submission

- thorough peer review by experienced researchers in your field

- rapid publication on acceptance

- support for research data, including large and complex data types

- gold Open Access which fosters wider collaboration and increased citations

- maximum visibility for your research: over 100M website views per year

At BMC, research is always in progress.

Learn more biomedcentral.com/submissions 